\title{
A diversidade linguística no ensino de português como língua adicional e língua estrangeira
}

DOI: http://dx.doi.org/10.21165/el.v49i2.2714

\author{
Juliana Bertucci Barbosa' \\ Deolinda de Jesus Freire ${ }^{2}$
}

\section{Resumo}

Este artigo tem como objetivo apresentar parte do resultado de uma pesquisa que vem sendo realizada no âmbito do Mestrado Profissional em Letras (Profletras) da Universidade Federal do Triângulo Mineiro (UFTM) desde 2016. Nessa etapa, elaboramos e aplicamos um questionário para diagnosticar conceitos que os professores da Educação Básica, alunos do mestrado profissional, têm sobre a diversidade linguística, tanto no Português Brasileiro quanto na Língua Adicional, em sua prática profissional. Também foi investigado como essa diversidade é abordada em suas aulas e se eles têm conhecimento do Celpe-Bras. A partir da análise das respostas do questionário, propomonos a refletir sobre posicionamentos teóricos que envolvem a formação de professores no que se refere à abordagem da diversidade linguística no ensino de língua portuguesa, bem como o plurilinguismo no Brasil.

Palavras-chave: português brasileiro; língua adicional; ensino de português.

\footnotetext{
1 Universidade Federal do Triângulo Mineiro (UFTM), Uberaba, Minas Gerais, Brasil; julianabertucci@gmail.com; http://orcid.org/0000-0002-1510-633X

2 Universidade Federal do Triângulo Mineiro (UFTM), Uberaba, Minas Gerais, Brasil; deolindajfreire@gmail.com; https://orcid.org/0000-0001-7372-9044
} 


\section{La diversidad lingüística en la enseñanza del portugués como lengua adicional y lengua extranjera}

\section{Resumen}

Este artículo tiene como objetivo presentar parte del resultado de una investigación que se realiza en el ámbito de la Maestría Profesional en Letras (Profletras) de la Universidade Federal do Triângulo Mineiro (UFTM) desde 2016. En esa etapa, elaboramos y aplicamos un cuestionario para diagnosticar conceptos que los profesores de la Educación Básica, alumnos de la maestría profesional, tienen sobre la diversidad lingüística del portugués en Brasil y lengua adicional en su práctica laboral. También se investigó como esa diversidad está abordada en sus clases y si ellos conocen el examen Celpe-Bras. A partir del análisis de las respuestas del cuestionario, proponemos una reflexión sobre posicionamientos teóricos que involucran la formación de profesores en lo que se refiere al abordaje de la diversidad lingüística en la enseñanza de lengua portuguesa, como también el plurilingüismo en Brasil.

Palabras clave: portugués brasileño; lengua adicional; enseñanza de portugués.

\section{Introdução}

Desde 2004, a língua portuguesa vive um período de crescimento cultural, bem como de divulgação, tanto no Brasil quanto no mundo. Fatores como a ampliação do letramento de boa parte da população, a inserção dos países na sociedade internacional e o crescimento da classe média - o que possibilitou uma produção e um consumo cultural mais letrado -, foram decisivos para fomentar maior interesse dos estrangeiros pelos países de língua portuguesa. Esse interesse também trouxe maior disposição para aprender o português como língua estrangeira e/ou adicional (OLIVEIRA, 2013).

No Brasil, o crescimento na oferta de cursos de português e a implantação do Certificado de Proficiência em Língua Portuguesa para Estrangeiros (Celpe-Bras) do Ministério da Educação são exemplos desse período promissor. Em consonância com esse momento, as licenciaturas em Letras das instituições de ensino superior estão implementando, em suas grades curriculares, disciplinas sobre o Português como Língua Adicional (PLA) e/ou Português como Língua Estrangeira (PLE) de forma a contemplar uma lacuna existente na formação dos futuros professores de língua portuguesa. Essa ação pode ser comprovada, por exemplo, com a nova grade dos cursos de Letras (Português e Espanhol; Português e Inglês) da Universidade Federal do Triângulo Mineiro (UFTM), que entrou em vigor no segundo semestre de 2018. 
Em razão do exposto, nossa proposta éapresentar parte do resultado de uma pesquisa que vem sendo realizada no âmbito do Programa de Pós-graduação Mestrado Profissional em Letras (Profletras) da UFTM desde 2016. A primeira etapa dessa pesquisa foi publicada em 2017 na revista Estudos Linguísticos com o título "Formação de professores e ensino de Português como Língua Adicional". Na segunda etapa, elaboramos e aplicamos um questionário para diagnosticar conceitos que os professores da Educação Básica, que são alunos do mestrado profissional, têm sobre a diversidade linguística do português no Brasil e no mundo e também sobre o conceito de língua adicional. Também foi investigado como essa diversidade é abordada em suas aulas e se eles têm conhecimento do exame Celpe-Bras. Esse questionário foi proposto como parte da avaliação diagnóstica da disciplina optativa "Produção de material didático para o ensino de Língua Portuguesa como Adicional", que faz parte da grade curricular do Profletras. É útil pontuar que os temas abordados nessa avaliação são discutidos ao longo das aulas da disciplina com aportes teóricos específicos. A avaliação diagnóstica tem se mostrado eficaz para iniciar as discussões teóricas sobre a língua portuguesa e seu ensino.

\section{Formação da diversidade linguística e ensino do português no Brasil}

Embora já se tenha reconhecido a variabilidade linguística como algo natural e inerente às línguas (LABOV, 2008 [1972], entre outros) e os documentos oficiais brasileiros, norteadores de ensino da língua portuguesa na Educação Básica - como Parâmetros Curriculares Nacionais (PCN) (BRASIL, 1997, 1998, 2000), Base Nacional Comum Curricular (BNCC) (BRASIL, 2018), Matriz de Referência do ENEM (INEP), edital de seleção de obras para o Programa Nacional do Livro Didático de Língua Portuguesa (PNLD) (BRASIL, 2019) -, indiquem a necessidade de um tratamento adequado das variações linguísticas (BORTONI-RICARDO, 2004), o reconhecimento da sócio-história do Português Brasileiro (PB) e das diferentes línguas faladas no país como um patrimônio cultural e linguístico ainda é pouco abordado em sala de aula.

Isso ocorre, principalmente, por ainda haver inúmeras crenças negativas sobre a língua e seus usos e usuários -, que se perpetuam e criam barreiras no processo de ensinar e aprender a língua portuguesa. Tais crenças, como, por exemplo, acreditar erroneamente que o Brasil é "um país monolíngue, porque seu povo só fala a língua portuguesa" ou que "existe uma variedade do português melhor do que outra", são resultantes, muitas vezes, do desconhecimento dos próprios professores da Educação Básica sobre a diversidade linguística do português no Brasil e no mundo. Além do mais, esses temas raramente estão presentes no cotidiano do ensino da língua na sala de aula, principalmente da Educação Básica.

Soma-se a isso, no cenário atual, um aumento de imigrantes nas escolas públicas brasileiras (OLIVEIRA, 2013), o que torna a diversidade linguística e cultural mais evidente, exigindo-se ainda mais uma formação docente diferenciada para atender as novas 
demandas que surgem no ambiente escolar. Segundo Oliveira (2013), a imigração é uma tendência a se multiplicar no Brasil e no mundo em razão, por exemplo, do mercado de trabalho, que tem sido uma das motivações para a presença de estrangeiros, ou ainda em razão de questões sócio-político-econômicas de países vulneráveis, obrigando pessoas a migrarem para outros países, como o Brasil. Diante desse contexto plural, se não houver ações, de preferência nas escolas, que visem a adotar medidas capazes de acolher diferentes línguas e culturas, e se as escolas não se prepararem para acolher essas diferenças, o risco que se corre não é apenas o da dificuldade de conviver com o outro, mas também o do aumento da intolerância, que pode suscitar a violência. Essa discussão, inclusive, foi tema da redação do exame Enem em 2012, cuja temática foi "Os Movimentos Imigratórios para o Brasil no século XXI". Esse dado corrobora a necessidade de discutirmos tais temáticas no ambiente escolar e universitário com o intuito de contribuir para uma formação mais consistente dos professores, que permita o debate sobre a compreensão e a aceitação do diferente, principalmente quando este se refere aos alunos na sala de aula.

Consideramos, então, que a diversidade linguística é um tema que deve estar presente nos cursos de formação inicial e continuada de professores da Educação Básica que atuam nas escolas brasileiras do século XXI. Isso porque o professor de língua portuguesa deve, entre outras ações: (i) reconhecer e trabalhar, em sala de aula, as características e as peculiaridades do Português Brasileiro; e (ii) tornar seus alunos mais sensíveis à diversidade cultural e linguística, incluindo a presente em sala de aula (FARACO, 2008). Assim, diante dessa problemática, parece-nos urgente refletir sobre a diversidade linguístico-cultural da língua portuguesa no Brasil e no mundo e relacioná-la ao ensino, sobretudo na formação do (futuro) professor. Para isso, é importante também, como fizemos neste artigo, conhecer o que pensam os professores de língua portuguesa sobre a diversidade e como trabalham este tema em sala de aula.

Por diversos fatores históricos e sociais (MATTOS E SILVA, 2008, 2009) ocorridos no Brasil desde o seu descobrimento, a língua majoritariamente em uso em nosso território é a língua portuguesa. Entretanto, essa língua, como quaisquer outras, não é isenta de variação. De acordo com Alkmim (2001, p. 33), seguindo a teoria da variação laboviana, "língua e variação são inseparáveis" e tal tendência faz jus à própria diversidade humana, que emprega os recursos linguísticos de diferentes formas, buscando atender diversos propósitos comunicativo-interacionais. Assim, se as línguas são marcadas pela diversidade, consequentemente, essa diversidade segmenta a língua em diversas normas. De acordo com Mattos e Silva (2006, p. 230), "pode-se hoje demonstrar que convivem, no Brasil, as 'normas vernáculas' ou o 'português popular brasileiro'; as 'normas cultas' ou o 'português culto brasileiro' e, no horizonte, paira [...] a 'norma padrão'".

Sendo assim, no ensino de língua portuguesa, o professor deve considerar as diferentes normas presentes no Brasil, que, em geral, constituem o Português Brasileiro. Ademais, são essas normas que fazem o português no Brasil ser diferente das outras variedades, 
como a europeia (Portugal), a asiática e a africana. As normas vernáculas do PB fazem parte do repertório linguístico de segmentos populares da sociedade brasileira e são marcadas de forma mais intensa pela variação, que é alvo de forte estigma social. Já as normas cultas (MATTOS E SILVA, 2006) são utilizadas pelos segmentos brasileiros de maior prestígio socioeconômico. O termo "culta", segundo Mattos e Silva (2006), atribuído à norma linguística da população de maior prestígio socioeconômico, está diretamente atrelado à cultura escrita, evidenciando o distanciamento das duas comunidades/normas (popular e culto) linguísticas em relação ao acesso aos bens culturais da sociedade. Ainda sobre a norma culta, Faraco (2008, p. 37) complementa que ela se caracteriza como um "conjunto de fenômenos linguísticos que ocorrem habitualmente no uso dos falantes letrados em situações mais monitoradas de fala e escrita". Com base nessas concepções, podemos inferir que há variações de nossa língua para cada grupo social do qual fazemos parte.

Cabe mencionarmos ainda, sucintamente, a norma padrão, que não representa nenhuma norma falada no Brasil, mas é apenas uma concepção idealizada e, de certo modo, uma diretriz para o controle da representação escrita da língua, "sendo qualificado de erro o que não segue esse modelo" (MATTOS E SILVA, 1995, p. 14). Faraco (2008) apresenta uma abordagem histórica do nome dado à norma padrão, nomeada por causa da necessidade de unificar a língua na sociedade feudal dos novos Estados Centrais Modernos (Europa), para excluir os dialetos regionais e se falar uma única língua, no intuito de criar um instrumento político-linguístico. Dessa forma, para Faraco (2008, p. 73), norma padrão é "uma codificação relativamente abstrata, uma baliza extraída do uso real para servir de referência, em sociedades marcadas por acentuada dialetação, a projetos políticos de uniformização lingüística"3.

Para não acentuar as diferenças de valores (muitas julgadas, dicotomicamente, como corretas ou erradas) em relação às normas linguísticas cultas e vernáculas no Brasil, pesquisadores da área dos estudos linguísticos têm apontado o conceito de contínuo linguístico. Dentre eles, podemos citar Bortoni-Ricardo (2004, p. 51), cujo argumento explicita que "[...] a terminologia tradicional carrega uma forte dose de preconceito", além da crença equivocada de que existem limites rígidos entre as normas. A autora propõe (BORTONI-RICARDO, 2004) a interpretação das interações verbo-sociais com base em três contínuos em contraponto à análise polarizada/dicotômica da língua: rural-urbano, oralidade-letramento e monitoramento estilístico. O contínuo linguístico, nessa teoria, é considerado como uma linha contínua em que transitam as normas vernáculas e as cultas em termos de adequação do registro às mais diversas situações sociocomunicativas. Nesse contínuo, dependendo da situação em que se encontra o falante, pode ocorrer, inclusive, uma interpenetração entre essas normas. Nessa perspectiva, não se pode afırmar que existe a superioridade de certos usos linguísticos em detrimento de outros.

3 Nas citações deste artigo, mantivemos a ortografia idêntica à obra original, incluindo uso do trema em " $u$ ". 
É pertinente ainda reconhecermos que essas diferentes normas constitutivas do português no Brasil são resultantes da sua construção social, histórica e cultural (MATTOS E SILVA, 1993, 2006), ou seja, a realidade linguística brasileira e a configuração de sua identidade podem ser entendidas quando retomamos alguns fatos da história externa do PB, como, por exemplo, o intenso contato entre línguas ocasionado pela presença marcante de diferentes etnias no Brasil durante os quatro primeiros séculos de formação de nosso país ${ }^{4}$. É por essa razão que Houaiss (1985, p. 91) já chamava atenção para o fato de que o Brasil "nasce com a diversidade", o que, de certo modo, faz-nos inferir que, no processo de formação do português no Brasil, saímos de um "multilinguismo generalizado" para sermos um país "multidialetal", com "multilinguismo localizado", para usarmos expressões de Mattos e Silva (1993). É por isso que, para entendermos a diversidade linguística presente no Brasil, é necessário retomarmos a participação dos diferentes povos que contribuíram para a formação do Português Brasileiro.

Em relação à participação indígena na formação do PB, Mattos e Silva $(1993,2006)$ comenta sua forte presença no período de colonização portuguesa. Tal fato também pode ser observado quando consultamos documentos da época, principalmente os do século $\mathrm{XVI}$, como as cartas de jesuítas ou tratados entre Portugal e Brasil. Numericamente, principalmente na primeira metade do século XVI, a população indígena era maior do que a dos portugueses colonizadores, o que obrigou estes últimos a aprender a língua dos tupinambás, ocorrendo, assim, uma situação de bilinguismo. Entretanto, à medida que a colonização portuguesa no Brasil continuou, algumas ações dos colonizadores provocaram "mudanças no cenário que impedia a difusão do português, facilitando seu processo de implementação [da língua portuguesa] paulatina no território brasileiro" (NOBRE, 2018, p. 3095). Segundo Nobre (2018, p. 3095), um exemplo disso foram:

[...] ações como a do governador-geral Mem de Sá, que, em 1557, eliminou mais de 130 aldeias dos tupinambás do Recôncavo Baiano; ações como a que dizimou os tupinambás das capitanias de Ilhéus e de Porto Seguro (informações que encontramos, entretanto, nas cartas XIV e XV, de Vilhena (1969 [1798-1799]), e em documentos transcritos por Mott (2010), em artigo riquíssimo sobre o sul da Bahia, levantam sérias dúvidas sobre a intensidade dessa dizimação); e ações, na capitania de Pernambuco, como a de seu donatário, Duarte Coelho, que dizimaram os índios ao longo de $300 \mathrm{~km}$ de costa.

Nobre (2018) também destaca o fato de que, nos primeiros dois séculos da colonização no Brasil, outras línguas europeias estiveram presentes. Para o autor, nos séculos XVI e XVII, foram falados no Brasil: o castelhano, o italiano, o inglês, o francês e o holandês.

4 Embora não seja foco deste artigo, obviamente, não poderíamos deixar de mencionar outros aspectos da história externa do PB que fazem parte da sua formação, como o precário sistema educacional brasileiro e o ruralismo da sociedade brasileira (MATTOS E SILVA, 2008). 
De acordo com Nobre (2018), a presença francesa, nesses primeiros séculos, deixou, principalmente no Rio de Janeiro (1555-1567) e no Maranhão (1612-1615), vestígios na toponímia local. O holandês deixou maiores vestígios no Nordeste, principalmente na Paraíba e no Rio Grande do Norte, devido à invasão holandesa de 1630 a 1653. Nesses estados, o contato entre holandeses e portugueses favoreceu influências na toponímia (nomes de lugares), na antroponímia e no vocabulário coloquial do português daquelas regiões. Já os espanhóis, segundo Nobre (2018), estiveram presentes desde o início da colonização em nosso país, e tinham sob seu domínio regiões que hoje se localizam no Sul do Brasil, principalmente os estados do Paraná, Santa Catarina e Rio Grande do Sul. Entretanto, cabe ressaltar que eles também participaram dos primeiros momentos da colonização em outras regiões, como o estado de São Paulo, tanto como colonos quanto como missionários (como exemplo, podemos citar o padre espanhol Anchieta).

Com relação à presença africana no Brasil, esta foi mais marcante, pois os africanos eram mão de obra escrava. Não podemos afirmar precisamente o ano em que os primeiros africanos foram trazidos para o Brasil, mas o que se sabe é que, em 1549, o tráfico negreiro foi oficializado. A partir de então, a relação entre África e Brasil esteve presente não só no processo de colonização brasileira, mas também após a proclamação da independência, em 1822, de modo que os africanos estão na base da formação da nação brasileira. Também não sabemos exatamente quantas línguas africanas chegaram ao Brasil a partir de 1549, porém, a estimativa de Petter (2006) é de terem aportado em território brasileiro, aproximadamente, de 200 a 300 línguas africanas.

Segundo Petter (2006), a predominância da etnia negra no Brasil foi notável, principalmente, no século XVIII. Documentos analisados pela pesquisadora apontam que, em 1700, a população total do Brasil era de aproximadamente trezentas mil pessoas, das quais cem mil eram brancos e cento e setenta mil escravizados de origem africana. Essa concentração de africanos no Brasil continua no período de 1700-1800 com as descobertas auríferas no estado de Minas Gerais, acarretando a necessidade de mão de obra para além do que havia sido necessário com a cultura de cana de açúcar.

Dessa forma, nos primeiros séculos de construção da nação brasileira, temos, na base da pirâmide populacional, os indígenas, os africanos e os afrodescendentes, de modo que a maneira como eles falavam contribuiu bastante na construção do PB. Mattos e Silva (2006) aponta, ainda, que, no século XVIII, também vieram muitos portugueses para o Brasil, acreditando na riqueza fácil que o ciclo do ouro oferecia, fato que também deixou marcas linguísticas ao português do Brasil.

Outro fator externo importante para a constituição da norma brasileira ocorreu no século XIX, com a vinda de imigrantes europeus e asiáticos para trabalharem no Brasil, principalmente nos estados das regiões Sul e Sudeste. Tais estrangeiros adquiriram a língua portuguesa sob condições especiais, como língua adicional, mas livres de 
normatizações. A chegada dos imigrantes de diversas nacionalidades, a partir do século XIX, contribuiu, indubitavelmente, para a ampliação da situação plurilíngue e dialetal brasileira.

Outros fatores sócio-históricos (e culturais) também foram importantes para a formação do PB, como fatores ligados à escolarização (ou a sua falta) no período de formação da nação brasileira, bem como a predominância do sistema rural, mas não iremos nos deter aqui nessas questões. O que buscamos evidenciar neste artigo, com a breve retomada histórica da constituição do PB, é a importância de o professor de língua portuguesa ter conhecimento dos fatos que levaram à formação da nossa língua e da nossa identidade, e, principalmente, o fato de que sempre estiveram presentes no Brasil diferentes línguas e culturas.

Afınal, éfundamental considerarmos as influências lexicais e gramaticais de outras línguas na constituição do PB, com especial destaque para as línguas indígenas e africanas. Entretanto, isso nem sempre é abordado em sala de aula na Educação Básica, pois, como veremos na análise dos nossos dados obtidos pelas respostas do questionário aplicado, alguns professores da Educação Básica, por exemplo, ignoram a presença indígena em território brasileiro, principalmente suas contribuições históricas, culturais e linguísticas.

Assim, no ensino do Português Brasileiro, seja como língua materna, seja como língua adicional - conceito abordado na próxima seção -, acreditamos ser relevante que o professor se aproprie de conhecimentos que devem ser levados para suas aulas com questões relacionadas à diversidade linguística, aos fatores sócio-históricos e culturais externos presentes na formação do PB e à pluralidade de normas que constituem a língua portuguesa no Brasil. Conforme sugere Bagno (2006, p. 19), devemos, ainda, considerar que o reconhecimento da

[...] existência de muitas normas lingüísticas diferentes é fundamental para que o ensino em nossas escolas seja conseqüente com o fato comprovado de que a norma lingüística ensinada em sala de aula é, em muitas situações, uma verdadeira "língua estrangeira" para o aluno que chega à escola proveniente de ambientes sociais onde a norma lingüística empregada no quotidiano é uma variedade de português não-padrão.

Com isso, alinhando-nos com o que defende Bagno (2006), é fundamental que escolas e instituições responsáveis pela formação inicial e continuada do professor desmistifiquem crenças infundadas, como a da unidade da língua portuguesa no Brasil, reconhecendo a verdadeira diversidade linguística brasileira e também outras línguas e culturas presentes em território nacional. Por isso, como já mencionado, temos como objetivos gerais, neste artigo, identificar e refletir sobre alguns pontos frágeis na formação continuada 
de professores de língua portuguesa no Brasil no que se refere à diversidade linguística e reflexões feitas a partir da abordagem do português como língua adicional e/ou estrangeira.

\section{Língua Estrangeira (PLE) ou Língua Adicional (PLA)?}

Além das questões relacionadas ao ensino do Português Brasileiro (PB) e à diversidade linguística e cultural presente no território brasileiro, também consideramos relevante que o professor de língua portuguesa da Educação Básica compreenda a diferença, embora não consensual, entre os conceitos de língua adicional e língua estrangeira (SCHLATTER; GARCEZ, 2012). Isso é importante devido, principalmente, ao aumento da presença de imigrantes nas escolas brasileiras. Além disso, é de extrema pertinência que o professor saiba da existência do Celpe-Bras e de seu funcionamento. Afinal, trata-se do único exame brasileiro oficial para certificar proficiência em português como língua estrangeira que explora características linguísticas e culturais brasileiras dentro de práticas sociais concretas (SCHLATTER, 1999).

Alguns pesquisadores, até mesmo dentro de perspectivas linguísticas distintas (como MOITA-LOPES, 1996, 2003; CORACINI, 2007; BERTUCCI BARBOSA; FREIRE, 2017 entre outros), evidenciam, por meio de suas investigações, que ainda há muito a se fazer em relação à formação inicial e continuada dos professores de línguas sobre os temas abordados neste artigo. Entre as ponderações, está o fato de ainda haver, nos cursos de licenciaturas em Letras, pouca preparação dos futuros professores para enfrentar contextos pluriculturais e plurilíngues ${ }^{5}$, bem como a diversidade linguística do Brasil. Vale ressaltar que esse é um dos motivos pelos quais o Mestrado Profissional em Letras, que visa à formação continuada dos professores, tem/inclui em seu currículo, por exemplo, a disciplina "Produção de materiais de português como língua adicional", cujas aulas e debates permitem refletir e investigar sobre tais temas.

Segundo Coracini (2007), disciplinas que visem a discussões críticas sobre o ensino da língua, como Linguística Aplicada e Sociolinguística Educacional, e produção de materiais didáticos são essenciais nos cursos de licenciaturas. Essas discussões podem, dependendo de como são abordadas, sensibilizar os (futuros) professores para o rico e complexo contexto sociolinguístico que os espera em muitos dos ambientes

5 Neste artigo, adotamos o termo plurilinguismo por se adequar ao propósito de nossas reflexões sobre o ensino do português brasileiro, pois nos alinhamos à ideia defendida pelo linguista LouisJean Calvet de que não existe um país monolíngue. Afinal, todos nós convivemos com várias línguas ou com as várias formas de uma mesma língua em nossa sociedade. Para Calvet, há duas formas de conceber o plurilinguismo: em primeiro lugar, "comme un phénomène individuel (un individu plurilingue, qui manie plusieurs langues, vit entre plusieurs langues, parce qu'il est issu d'un couple bilingue, ou qu'il a beaucoup voyagé ou beaucoup étudié)"; e em segundo, "comme un phénomène collectif (une communauté plurilingue, dans laquelle coexistent plusieurs langues).". 
onde exercerão sua prática docente. Assim, partilhamos dos apontamentos de Coracini (2007, p. 126) quando afirma que o docente "precisa estar preparado para lidar com os conflitos em sala de aula" e que esses conflitos, juntamente com a falta de preparo do professor, acabam gerando estigmas e preconceitos que são vivenciados pelos alunos na Educação Básica de forma geral.

No cenário atual, em que podem estar presentes em sala de aula diferentes normas linguísticas do PB, além de outras línguas, é fundamental saber considerar, na preparação de materiais didáticos e nas avaliações realizadas em classe, a distinção entre língua adicional e língua estrangeira. Tradicionalmente, em um primeiro momento, estabeleceuse a diferença entre língua estrangeira e segunda língua. Se a língua estudada não é falada na comunidade em que vive o aluno, temos a situação de uma língua estrangeira, como seria, por exemplo, o caso do ensino do português na Polônia; o português seria, para o aluno polonês, uma língua estrangeira. Se a língua estudada é falada na comunidade em que vive o aprendiz, ela seria, então, definida como segunda língua, caso, por exemplo, do aluno polonês que estuda português no Brasil.

A não exatidão do termo "segunda língua", no entanto, pode ser facilmente observada, principalmente quando se levam em consideração as características sociais e culturais do aluno. Muitos alunos vivem essa situação - como filhos de imigrantes, índios, surdos, pois já conhecem mais de uma língua, por exemplo. Afinal, podemos ter um aluno polonês que, além de viver no Brasil para estudar português, comunica-se em sua língua materna (polonês) e ainda fala inglês. Nessa situação descrita, esse aluno teria o português não como segunda língua, mas como terceira. Ademais, também é problemático considerar língua "estrangeira" (no sentido de "estranho"), por exemplo, a língua alemã no Brasil, pois, apesar de ser considerada uma língua estrangeira (por ser a língua oficial da Alemanha), há comunidades no Brasil, em que, além do português, fala-se também o alemão. Nesse contexto, um aluno, que pode estar em uma escola bilíngue no Brasil e estudar alemão, não tem a língua alemã como estrangeira, mas como outra língua apreendida juntamente com português (alemão não seria língua estrangeira, neste caso).

Assim, considerando essas e outras problemáticas, quando nos propomos a ensinar uma língua para quem já tem conhecimento de pelo menos uma, surge a questão de como nomear essa outra língua. É o caso do que acontece com os imigrantes que estão no Brasil. Segundo Schlatter e Garcez (2012), todos já temos pelo menos uma língua, seja o português, uma língua indígena, a língua dos pais imigrantes ou a de sinais, mas alguns alunos possuem mais de uma língua. Desse modo, a língua que ele vai estudar na escola pode não ser uma segunda língua ou uma língua estrangeira, mas será, em

Ademais, de acordo com Leonarda Jacinto José Maria Menezes, plurilinguismo não se refere apenas ao domínio de diversas línguas, mas também à estreita relação entre língua e cultura, conceito que dialoga diretamente com os contextos aqui mencionados. 
uma definição mais adequada, uma língua que podemos nomear de "adicional". Dessa forma, o emprego do termo "adicional" parece-nos mais apropriado porque não há necessidade de se detalhar o contexto geográfico (língua do país vizinho, língua franca ou internacional) ou mesmo as características linguísticas individuais do aluno (segunda ou terceira língua) ${ }^{6}$.

Para Schlatter e Garcez (2012), a "adição" de outra língua às línguas que o aluno já possui deve, idealmente, gerar uma convivência pacífica entre elas, sem atritos, pelo fato de que, em geral, atendem a objetivos diferentes. A língua adicional, por exemplo, poderá ser a língua do trabalho, de estudo ou de convivência social (lazer). A língua adicional seria, nessa concepção, uma espécie de distribuição complementar com a língua materna, que será (ou não) preferencialmente utilizada em outros contextos do indivíduo, tais como, na vida familiar, com os amigos, nos serviços públicos.

Dessa forma, no Brasil, quando consideramos que um aluno tem o português como língua adicional, defendemos também a concepção de que seu ensino é um direito com benefícios para toda a sociedade. Nessa perspectiva, negar ao aluno o acesso a uma língua adicional não é apenas uma maneira de excluí-lo, impedindo-o de exercer sua cidadania, é uma forma de atrasar o desenvolvimento de um país com nítidos contextos plurilíngues e pluriculturais no mundo atual.

\section{Procedimentos metodológicos}

Para parte da pesquisa desenvolvida em 2018, continuando investigações realizadas desde 2016 sobre o tema, elaboramos e aplicamos, como já mencionado, um questionário com oito questões abertas, são elas: 1) Exponha seu conhecimento sobre a origem sóciohistórica da Língua Portuguesa; 2) Disserte sobre o que você entende por diversidade linguística; 3) Reflita sobre a diversidade linguística da Língua Portuguesa no Brasil e no mundo; 4) Explique como a diversidade linguística da Língua Portuguesa é contemplada em suas aulas; 5) O que você entende por política linguística e como você a percebe na prática pedagógica da escola; 6) O que você compreende por "Língua Adicional"; 7) Você conhece o Celpe-Bras? Explique o que é e como funciona; 8) Após ler o fragmento de um texto jornalístico entregue pela professora, disserte sobre a situação vivida pela

6 É útil destacar que existe a opção de dizer "segunda língua" (e não "língua segunda"), em contexto "internacional", para indicar todas as línguas que foram aprendidas depois da primeira (L1 ou língua materna). Há ainda uma disciplina intitulada "Second Language Acquisition" (SLA), traduzida para o português como "Aquisição de Segunda Língua", que discute teorias relacionadas à aquisição das línguas. Ademais, este também é o título do livro de Vera Lúcia Menezes de Oliveira e Paiva, publicado pela Parábola Editorial em 2014, que aborda, no contexto brasileiro, algumas das teorias mais conhecidas nessa área de pesquisa. 
menina síria na escola e o porquê de sua dificuldade. Coloque-se no lugar da professora da menina, o que você faria?

Nosso principal objetivo, com aplicação do questionário, foi diagnosticar conceitos e conhecimentos que os professores da Educação Básica, alunos do Programa de Mestrado Profissional em Letras (Profletras) de uma universidade pública do Triângulo Mineiro - professores de língua portuguesa do Ensino Fundamental -, têm sobre a diversidade linguística do português no Brasil e no mundo e sobre sua abordagem em sala de aula. Além desse tema, na questão de número 6, investigamos o conhecimento dos participantes sobre a língua adicional, o que nos possibilitou revisitar o conceito de língua materna, língua franca, língua nacional e transnacional, língua oficial, língua segunda e língua estrangeira; e na questão de número 7, avaliamos o conhecimento dos participantes acerca do Celpe-Bras.

Esse questionário, com as mesmas oito questões, foi aplicado em dois momentos distintos ${ }^{8}$, em uma sala de aula da universidade, no âmbito da disciplina optativa intitulada "Produção de material didático para o ensino de Língua Portuguesa como Adicional". Essa disciplina faz parte da grade curricular do Profletras aprovada pela CAPES e tem carga horária de 45h/a. Tivemos como participantes da pesquisa um total de 14 alunos, que foram nomeados por letras alfabéticas para que suas identidades sejam preservadas.

A primeira aplicação do questionário ocorreu no primeiro dia de aula, antes de os alunosprofessores terem contato com o conteúdo da disciplina. O segundo momento aconteceu no último dia de aula, após as leituras dos aportes teóricos e das discussões sobre os temas abordados na optativa. Nessa segunda aplicação do questionário, optamos pela reescrita das respostas anteriormente elaboradas pelos alunos-professores. Nossa intenção também foi a de verificar se, após os debates realizados durante o desenvolvimento da disciplina, os respondentes alterariam concepções ou conhecimentos e/ou apontariam novos saberes sobre diversidade linguística, constituição do PB, língua adicional etc.

Após aplicarmos os questionários, analisamos as respostas quanti e qualitativamente. Inicialmente, realizamos o levantamento quantitativo, por meio de tabelas no Excel, de respostas e de indicações dadas pelos mestrandos na primeira e na segunda aplicação

7 Para responder a questão de número 8 (oito), entregamos aos alunos-professores fragmentos, mais exatamente, 5 (cinco) parágrafos de um total de 12 (doze), do texto "Autista, não: imigrante" de Vitor Hugo Brandalise, publicado no caderno Educação do jornal O Estado de S. Paulo em 19 de março de 2017. Nesta matéria, Brandalise discorre sobre crianças imigrantes, ainda em fase de adaptação, que são tratadas por escolas de São Paulo como casos de saúde mental.

80 questionário aplicado nos dois momentos distintos continha as mesmas 8 (oito) questões. Para a reescrita, os alunos-professores tiveram acesso às respostas da primeira aplicação para que pudessem revisá-las após as leituras e os debates proporcionados pela disciplina. 
do questionário (por exemplo, quantificamos definições e citações de comunidades que se repetiam nas respostas). Em seguida, realizamos ponderações qualitativas das respostas dadas (MINAYO, 2007), por meio da análise de conteúdos e de conceitos que apareceram nas respostas produzidas pelos mestrandos na primeira e na segunda aplicação (reescrita) do questionário.

Cabe destacar que, das oito questões, duas não serão abordadas nesse artigo, são elas: a de número 5 sobre o conceito de política linguística e sua prática em sala de aula; e a de número 8 que aborda um fragmento jornalístico sobre a situação de uma menina síria em sala de aula. As demais questões versavam sobre a origem sócio-histórica da Língua Portuguesa, a diversidade linguística do Português Brasileiro (PB) e sua abordagem em sala de aula, o conceito de Língua Adicional e o exame Celpe-Bras. É sobre esses temas que a análise na próxima seção se deterá, com o intuito de propor um breve panorama, no contexto delimitado, sobre a diversidade linguística no ensino do português como língua adicional e/ou estrangeira.

\section{Leitura e análise das respostas do questionário avaliativo}

Antes de apresentarmos a análise das respostas sobre a diversidade linguística do português brasileiro, interessa-nos expor brevemente algumas das respostas acerca do conhecimento dos alunos-professores no que se refere à formação sócio-histórica da língua portuguesa, abordada na primeira questão do questionário. Nesse momento, o objetivo era mapear o que eles conheciam sobre o tema para iniciar as leituras e os debates sobre diversidade linguística, pontuando como as línguas neolatinas surgiram a partir de uma intensa pluralidade de línguas e culturas de povos que se fizeram presentes por muitos séculos na Península Ibérica. Na primeira aplicação, as respostas evidenciaram que os alunos-professores tinham pouquíssimo contato com a temática. Os alunos A e B, por exemplo, afirmaram que o português nasceu a partir "do latim e do grego", confundindo influência com origem da língua. Das 14 respostas, dois alunos assumiram não saber nada sobre a origem da língua portuguesa e da constituição do PB e dez apenas afırmaram que o português "nasceu" do latim e/ou do latim vulgar. Apenas um pontuou que o português sofreu influência léxica do árabe, sem especificar o porquê. Outros alunos reconheceram que o francês, o italiano e o espanhol têm a mesma origem do português, ou seja, derivaram do latim. No entanto, outros defenderam que o português sofreu influência do francês, italiano e espanhol em sua formação, como se todas essas línguas não tivessem surgido sob um mesmo contexto social, histórico e cultural com raízes comuns.

A partir das respostas, percebemos que era necessário retomar, mesmo que sucintamente, a origem sócio-histórica da língua portuguesa e suas especificidades, como, por exemplo, a convivência geográfica, bem como linguística e cultural, dos povos conquistados pelos romanos com os povos do norte da Europa e os árabes. As leituras sobre esse 
período de formação, a partir de uma perspectiva histórica, interessaram sobremaneira aos alunos-professores, pois era uma lacuna que eles tinham na contextualização da origem e formação das línguas da Península Ibérica. Uma das novidades, para eles, foi estudar a presença dos árabes na península de 711 a 1492, ou seja, oito séculos, tempo superior à invasão dos romanos, visigodos e outros povos provenientes, principalmente, do norte do continente europeu. Surgiu, assim, certa curiosidade sobre a influência do árabe no léxico, o que os motivou a buscar palavras da língua portuguesa cuja origem se relacionasse com a cultura árabe, como almofada, saguão, açúcar, berinjela; além de outros vocábulos que evidenciam intensa convivência cultural, como alguns objetos decorativos: tapete, cortina, azulejo etc. Esse interesse pode ser comprovado na revisão e reescrita da questão, em que a maioria dos alunos mencionou a influência árabe, além da latina ${ }^{9}$, na formação da língua portuguesa na Península Ibérica, tema que os alunos admitiram não conhecer a ponto de refletir sobre as diferenças do português europeu e do brasileiro. Como exemplo, inserimos a seguir a reescrita da resposta do aluno $A$, que afirmou:

[a língua] sofre influência também dos germânicos que de 409 a 711 d.C. imigraram para a Península contribuindo para uma diferenciação regional da língua que não é falada de modo uniforme. A partir de 711 acontece a invasão moura sendo imposto o árabe, mas a população continua a falar o romance. No entanto a língua vai sofrendo mudanças e influências árabes. (Fragmento aluno A) $)^{10}$.

Após a questão sobre a origem sócio-histórica da língua, pedimos aos alunos-professores que refletissem sobre o conceito de diversidade linguística, a formação do Português Brasileiro (PB) e a diversidade linguística do português no Brasil e no mundo, bem como a presença dessa diversidade em suas aulas. Nessas questões, os alunos demonstraram

9 Para o debate sobre a formação histórica e linguística da Península Ibérica, foi sugerida a leitura do artigo "Breve Histórico da Península Ibérica" de Nilsa Areán-García, publicado pelo Círculo Fluminense de Estudos Filológicos e Linguísticos na Revista Philologus, n. 45, em 2009. Trata-se de um texto que apresenta de forma didática, inclusive com o recurso de mapas, as invasões ocorridas no período de 210 a.C, data da chegada dos romanos na península, até a concretização da reconquista cristã por Fernando e Isabel, conhecidos como reis católicos, em 1492. Esse artigo foi sugerido porque os alunos-professores demonstraram desconhecer fatos essenciais sobre a formação histórica da língua, consequentemente da cultura, do português na Europa. Após essa primeira leitura, foram discutidas especificidades históricas da formação da língua portuguesa no Brasil, inclusive com a abordagem de fatos históricos, como a expulsão dos jesuítas com o decreto do Marquês de Pombal, que contribuíram para o apagamento das línguas e culturas indígenas, e dos ideais românticos a partir do século XIX que fortaleceram os debates e a instituição da língua e da cultura nacional.

10 Os fragmentos dos textos de todos os alunos-professores mantiveram a escrita original, ou seja, não houve correção textual para a inserção de citação no artigo. 
pouco conhecimento sobre a presença da língua portuguesa nos continentes africanos e asiáticos. Do total de 14, apenas três alunos mencionaram sua presença na Ásia e na África, destacando países como Angola, Moçambique, Guiné Bissau e Cabo Verde. Ainda que tenham citado esses países, os alunos demonstraram muita dificuldade em expor quais seriam as especificidades da diversidade nos diferentes continentes. Essa mesma dificuldade reflete-se no que se refere à influência das línguas indígenas na constituição da diversidade linguística do português no Brasil: apenas dois alunos lembraram-se da existência dessas línguas como um dos aspectos linguísticos determinantes para a formação das variedades linguísticas em território brasileiro.

Após as aulas, na reescrita, houve uma revisão atenta, o aluno A, por exemplo, afirmou, antes das leituras e debates, que a diversidade linguística está relacionada a questões sociais e culturais de cada grupo, destacando que há prestígio da norma culta da língua em classes sociais mais altas. Na reescrita, esse mesmo aluno reconhece o contato da língua portuguesa com as línguas indígenas e africanas em território nacional, além de ressaltar diversos países em que essa língua é falada, como, por exemplo, Angola, Moçambique e Timor Leste. Na revisão dessa questão, o que mais parece ter impressionado os alunos foi saber que ainda são faladas por volta de 170 línguas indígenas no Brasil. Dois alunos (C e F) refletem sobre o português ser considerada a única língua comum no Brasil, o aluno F ainda conclui que a língua, definitivamente, não é homogênea, e que o melhor seria falar em "línguas portuguesas" - e não língua portuguesa -, como podemos comprovar nos fragmentos abaixo:

Criou-se em nosso imaginário uma comunidade constituída basicamente pelas "três raças formadoras" (o português, o indígena e o negro), mas expressando-se em uma língua comum - o português. Essa imagem, no entanto, não expressa a realidade do que ocorre em inúmeras regiões do país, onde vários grupos de brasileiros falam também outras línguas que expressam visões de mundo, valores e significados fundamentais para a história e a identidade desses grupos e da própria nação. (Fragmento aluno C).

A Língua Portuguesa pode ser definida como um polígono multifacetado, resultante da contribuição da língua de diversos povos que aqui estiveram. Assim, a Língua Portuguesa como a conhecemos hoje é resultado de uma gama incontável de contribuições de povos portugueses, indígenas, africanos e imigrantes que aqui se instalaram e contribuíram com suas tradições e culturas para formação da nossa língua. Temos ainda que lembrar [que o Brasil] não é um território monolíngue, mas multilíngue, no qual convivem cerca de 200 línguas, sendo 170 indígenas [...] mais adequado seria nos referirmos à "Línguas Portuguesas" [...] (Fragmento aluno F). 
Na revisão e reescrita de sua primeira resposta, o aluno $C$ percebe que a imagem de uma língua única - o português - em território brasileiro não expressa a complexidade linguística e cultural dos povos que contribuíram para a construção de nossa identidade: o português, o indígena, o negro, entre outros. Assim, o aluno, sem afirmar explicitamente, corrobora a ideia de que o Brasil não é um país monolíngue. O aluno F confirma essa leitura de forma mais incisiva ao afirmar que nosso país não é um território monolíngue, quando se considera a convivência das diversas línguas indígenas faladas atualmente e as contribuições dos povos africanos e dos imigrantes.

No que se refere ao conceito de diversidade linguística no Brasil, grande parte dos alunos reconhece que ela é marcada por fatores econômicos, socioeconômicos e geográficos, além do gênero e da idade. $O$ aluno $F$, mencionado anteriormente, foi o único a propor uma reflexão mais aprofundada sobre o tema, afırmando que a diversidade linguística

\begin{abstract}
[...] deve ser entendida como um conjunto de variações da língua que dependem de diferentes fatores: culturais, regionais, sociais, etários e gênero, estando presente na escrita e na fala. É a diversidade que evidencia a identidade de cada grupo, que se manifesta pelas singularidades no uso da língua. A diversidade reflete o meio no qual ela se desenvolve, por isso é alvo de preconceito e estigma social, que se manifesta através do preconceito linguístico. (Fragmento aluno F).
\end{abstract}

Em relação à revisão desta questão, a reescrita foi incipiente, pois os alunos demonstraram, de maneira geral, pouca aderência às reflexões propostas pela disciplina. Percebemos que ainda é necessário apresentar mais fatos e estudos sobre a constituição do português no Brasil para que os alunos/professores consigam apropriar-se dessa discussão e defender suas próprias reflexões.

Sobre a abordagem da diversidade linguística nas aulas de língua portuguesa, a maioria dos mestrandos indicou apenas a necessidade de ensinar ao seu aluno na escola a variante culta do português e sua adequação em diversos espaços e ambientes, não mencionando a necessidade de considerar as outras normas, incluindo as vernáculas ${ }^{11}$,

11 Recuperando as discussões sobre normas linguísticas, é importante destacar que não podemos conceber norma linguística sem antes reconhecer que as línguas variam e mudam com o tempo e que, em cada época, normas vernaculares (ou populares) e normas cultas competem com normas de sincronias passadas, como se existissem diferentes normas ou gramáticas em competição em um mesmo período de tempo. O conceito de norma, como já apontando neste artigo (subseção "Formação da diversidade linguística e ensino do português no Brasil"), é bastante polissêmico e polêmico, envolvendo diferentes variáveis e motivações. Para Faraco (2008), a norma(s) culta(s) é um conjunto de regras e padrões linguísticos usados por falantes letrados em contexto de maior monitoramento. É considerada a variedade linguística de maior prestígio. Já a(s) norma(s) vernacular(es) ou popular(es), segundo Mattos e Silva (2006), consiste(m) no conjunto de regras 
em suas aulas para evitar situações de preconceito linguístico. Na primeira escrita, antes das aulas e debates propostos pela disciplina, os alunos destacaram apenas a abordagem da norma culta como indício do ensino de diversidade linguística em suas aulas.

Na reescrita, o aluno D, por exemplo, mencionou que "temos uma grande diversidade linguística no Brasil devido à influência dos índios, negros e imigrantes", ponderando que essa influência é ignorada nos materiais didáticos. O aluno ainda afirmou que procura, durante suas aulas, "mostrar para o aluno que a língua não é pura e que foi constituída com outras culturas". Outro aluno fez questão de ponderar em sua resposta que "antes do Profletras", a diferença pontuada em suas aulas "referia-se apenas com relação a fatores diatópicos, diastráticos e diacrônicos". Após o ingresso no mestrado, esse professor leva em consideração para suas aulas as contribuições de outros povos, principalmente os africanos, já que alguns de seus alunos são oriundos de quilombolas, logo, comunicamse em um dialeto. Assim, como professor, ele aprendeu a respeitar a variedade do aluno ao refletir sobre a pertinência do aprendizado da norma culta, pois acredita que "o aluno deve conhecer as variedades [da língua] para fazer uso consciente e competente em diferentes situações comunicativas".

Após a abordagem da diversidade linguística da língua portuguesa e sua prática em sala de aula, os alunos foram questionados sobre o conceito de Língua Adicional e o exame Celpe-Bras. Com relação ao primeiro tema, a maioria dos alunos afirmou que não reconhecia o termo, alguns relacionaram a língua adicional com a estrangeira e outros mencionaram equivocadamente que Libras seria a adicional para um surdo no Brasil. Nessa questão, ficou evidente o desconhecimento sobre o ensino do português como língua adicional ou estrangeira. Apenas o aluno E mencionou que se trata de uma "língua adicionada ao repertório dos falantes devido a alguma necessidade", entre as quais a profissional, a acadêmica, a política ou, ainda, a mudança de país.

Ainda que esse conceito tenha sido discutido e revisado durante as aulas, indicando sua diferenciação com relação à língua materna, à língua estrangeira e à segunda língua, seguindo os pressupostos de Schlatter e Garcez (2012), na revisão e reescrita sobre o tema, os alunos ainda demonstraram muita dificuldade em compreender tais conceitos. O aluno B, por exemplo, afirmou, simplificadamente, que adicional é uma língua "em que adquirimos fluência além da língua materna. Também pode ser uma língua estrangeira, uma língua de imigração, de herança, de integração". Já o aluno C ponderou que se trata

ou padrões linguísticos de falantes em situações de menor monitoramento de classes sociais menos prestigiadas. Partimos do princípio de que para que um aluno consiga adequar a sua fala/escrita aos diferentes domínios sociais, a(s) norma(s) culta(s) deve(m) ser ensinada(s) na escola, entretanto, mas não deve ser a única (norma) privilegiada no processo de conhecimento linguístico proporcionado pelos professores. As normas vernaculares (ou populares) merecem ser debatidas em sala de aula também, pois elas ilustram a heterogeneidade linguística adquirida espontaneamente por todos nós brasileiros. 
de "uma terceira língua aprendida pelo indivíduo. Para ser adicional, a pessoa deve usar com frequência". As respostas da reescrita evidenciam a dificuldade dos alunos em se apropriar desses conceitos que, para eles, são uma reflexão bem recente.

Sobre o Celpe-Bras, a maioria dos alunos afirmou não saber do que se trata nem como funciona. Do total de 14, sete alunos nunca haviam ouvido falar do exame. Três acreditam que se trata de um órgão ou programa brasileiro de apoio ao estrangeiro no Brasil e ao brasileiro no exterior e apenas quatro alunos afirmaram que se trata de um tipo de exame de proficiência, mas que não sabem exatamente como funciona. Na reescrita, ao contrário do que aconteceu com o conceito de língua adicional, houve uma revisão consistente, pois todos os alunos expuseram de forma clara o conceito do exame e compreenderam como funciona, destacando sua aplicação e o método sociocomunicativo de avaliação.

O aluno D, por exemplo, afirmou que o Celpe-Bras é

[...] um certificado de proficiência de língua portuguesa para estrangeiros. É o único aceito para o estrangeiro que quer trabalhar no Brasil. 0 exame se propõe a avaliar se o indivíduo sabe usar a língua portuguesa em uma situação real de comunicação. É composto por duas etapas, uma escrita e outra oral. A primeira tem duração de 3 horas e a segunda de 20 minutos. (Fragmento aluno D).

Já a aluna $\mathrm{N}$ reconheceu que se trata de um certificado de proficiência do Português como língua estrangeira, destacando que

[o Celpe-Bras] existe no Brasil e em vários países. O candidato faz uma avaliação em forma de tarefas oral e escrita, podendo adquirir certificado em uma das quatro modalidades: intermediaria, intermediaria superior, avançada e avançada superior. 0 exame é aplicado pelo INEP em faculdades credenciadas duas vezes por ano, sendo exigido para estrangeiros que pretendem cursar pós-graduação ou trabalhar no Brasil. (Fragmento aluno N).

Nessas reescritas, os detalhes de como funciona o exame, inclusive com menção às partes que o compõem e à forma de aplicação, evidenciam que houve uma compreensão substancial sobre essa certificação da língua portuguesa. Ademais, as aulas e os debates proporcionados pela disciplina contribuíram para uma reflexão mais consistente da abordagem da língua portuguesa como adicional e/ou estrangeira, principalmente com o conhecimento do Celpe-Bras e seu funcionamento, e a importância desse aporte teórico para o ensino do português na Educação Básica. 


\section{Considerações finais}

Após a leitura e análise das questões do questionário aplicado, percebemos que os alunos do Profletras, professores da Educação Básica, demonstraram ter conhecimentos muito frágeis e superficiais, no que se refere ao conceito de diversidade linguística, à presença da língua portuguesa no Brasil e no mundo e à forma como a diversidade do português é contemplada em suas aulas. Em suas respostas, na primeira aplicação do questionário, os alunos não mencionam a presença das línguas indígenas e africanas na formação da diversidade da língua portuguesa no Brasil. Aliás, eles sequer reconhecem a presença de línguas indígenas no Brasil. Na reescrita, quando aplicamos novamente 0 mesmo questionário, momento em que os alunos puderam reescrever suas respostas, a maior parte dos alunos mencionou, principalmente, as línguas indígenas. É relevante destacar que os alunos se surpreenderam, durante as aulas, com o número de línguas indígenas ainda faladas em território nacional atualmente e afirmaram que não sabem nada a respeito dessas línguas e que não teriam condições de preparar uma aula que incluísse tal tema. É pertinente destacar também a escassa referência teórica desses alunos sobre a influência de línguas estrangeiras no Português Brasileiro, como, por exemplo, as línguas italiana e alemã. De modo geral, os mestrandos-professores não reconhecem as comunidades de imigrantes, que estiveram (e ainda estão) em diversas partes do Brasil, como povos que influenciaram a constituição linguística brasileira.

Com relação às questões que abordaram a língua adicional e o Celpe-Bras, os alunos demonstram que a disciplina foi importante para que conhecessem e refletissem sobre ambos os conceitos. No entanto, as leituras e os debates sobre o conceito de adicional não foram suficientes para que conseguissem revisar o tema na reescrita, pois não se apropriaram das diferenças entre os termos, parecendo que é tudo língua estrangeira com nomes diferenciados. Esse dado nos revela que essa dificuldade está relacionada ao aporte teórico sobre o tema, que ainda é recente na academia e no mundo universitário, carecendo, de fato, de reflexões mais pontuais. Sobre o exame de certificado de proficiência em português, foi consistente a revisão que fizeram na reescrita do questionário. Os alunos, de forma unânime, compreenderam seu conceito e seu funcionamento e demonstraram muito interesse em discutir sobre o tema. Um dos pontos preocupantes que nos revelaram a leitura e a análise das respostas é o fato de o Celpe-Bras ser tão desconhecido no ambiente escolar e na Educação Básica, de modo geral.

Consideramos que nossos resultados indicam a necessidade de se repensar a formação inicial e continuada dos professores de língua portuguesa no que se refere aos temas abordados em nosso trabalho: conceitos como diversidade linguística no Brasil e no mundo, diferenças das variantes do Português Brasileiro, Língua Adicional e Celpe-Bras deveriam ter um lugar mais definido nos currículos para propiciar uma formação mais aprofundada dos (futuros) professores. Os resultados demonstram também que discutir o ensino do português como língua estrangeira e/ou adicional contribui para que os professores reflitam sobre sua prática e possam desenvolver estratégias de ensino da 
língua materna a partir do conhecimento adquirido nas discussões sobre o português como língua adicional e estrangeira.

Afinal, considerar a diversidade linguística brasileira na sala de aula, seja como língua materna ou adicional, é, antes de tudo, uma atitude reveladora de respeito ao próprio usuário da língua, possibilitando que ele desenvolva a competência linguística necessária para o reconhecimento de que cada variedade linguística tem o seu lugar e o seu papel no âmbito do processo comunicativo para o qual a língua é utilizada. A escola que, ao longo da nossa história, sempre esteve mais próxima dos interesses de grupos dominantes, omitindo muitos fatos e reinterpretando outros tantos, depara-se, nos tempos atuais, com a possibilidade de reparar um dos muitos enganos a respeito das línguas faladas no Brasil e das diferentes normas do PB presentes em nosso país. Contudo, é preciso que essa inclusão da diversidade linguística nas aulas de língua portuguesa esteja acompanhada de uma melhor formação do professor, sendo essencial que ele tenha acesso a um sólido arcabouço teórico a respeito desses assuntos, para que o trabalho não seja, como muitas vezes acontece, interpretado como uma tentativa de extinguir o ensino da gramática normativa ou como a instituição do "tudo pode" na língua (senso comum equivocado). Nessa busca por um aprimoramento da formação docente, é cada vez mais necessário recorrermos à extensa literatura que tem se produzido acerca desses assuntos debatidos no meio acadêmico.

Para seguir com nossas reflexões sobre a formação docente, em uma próxima etapa, ampliaremos a pesquisa para investigar a elaboração dos materiais de língua portuguesa para estrangeiros produzidos na disciplina "Produção de material didático para o ensino de Língua Portuguesa como Adicional". Em nossa prática, percebemos que essa abordagem permite aos professores desenvolver um olhar mais crítico para pensar a diversidade cultural e linguística na sala de aula, a partir do desafio de adaptar o material didático para o ensino de português como língua estrangeira e/ou adicional.

\section{REFERÊNCIAS}

ALKMIM, T. M. Sociolingüística. Parte I. In: MUSSALIN, F.; BENTES, A. C. (org.). Introdução à Lingüística: domínios e fronteiras. v. 1. São Paulo: Cortez, 2001. p. 21-47.

BAGNO, M. Preconceito linguístico: o que é, como se faz. 46. ed. São Paulo: Edições Loyola, 2006.

BERTUCCI BARBOSA, J.; FREIRE, D. J. Formação de professores e ensino de Português como Língua Adicional. Estudos Linguísticos, v. 46, n. 2, p. 593-602, 2017. 
BORTONI-RICARDO, S. M. Educação em língua materna: a sociolingüística na sala de aula. São Paulo: Parábola Editorial, 2004.

BRASIL. Ministério da Educação. Guia do livro didático PNLD. Brasília: Ministério da Educação, 2019.

BRASIL. Base Nacional Comum Curricular (BNCC). Educação é a Base. Brasília, MEC/ CONSED/UNDIME, 2018. Disponível em: http://basenacionalcomum.mec.gov.br/ images/BNCC_El_EF_110518_versaofinal_site.pdf. Acesso em: 02 jun. 2019.

BRASIL. Ministério da Educação. Instituto Nacional de Estudos e Pesquisas Educacionais Anísio Teixeira - INEP. INEP Matriz de referência do ENEM. 2012. Disponível em: https://bit.ly/30iiwut. Acesso em set. 2019.

BRASIL. Ministério da Educação. Secretaria de Educação Média e Tecnológica Parâmetros curriculares nacionais: introdução. Brasília: MEC/SEF, 1997.

BRASIL. Ministério da Educação. Secretaria de Educação Média e Tecnológica Parâmetros curriculares nacionais: introdução aos parâmetros curriculares nacionais do Ensino Fundamental II. Brasília: MEC/SEF, 1998.

BRASIL. Ministério da Educação. Secretaria de Educação Média e Tecnológica Parâmetros Curriculares Nacionais: Ensino Médio - Parte I - Bases Legais. Brasília: $\mathrm{MEC} / \mathrm{SEF}, 2000$.

CALVET, L.-J. Identité et plurilinguisme, dans 1 ère Table Ronde Identité et multiculturalisme. Trois espaces linguistiques face aux défis de la mondialisation. Paris: 2001.

CORACINI, M. J. R. F. A Celebração do Outro: arquivo, memória e identidade: línguas (materna e estrangeira), plurilinguismo e tradução. Campinas: Mercado de Letras, 2007.

FARACO, C. A. Norma Culta Brasileira: desatando alguns nós. São Paulo: Parábola Editorial, 2008.

HOUAISS, A. O português no Brasil. Rio de Janeiro: Unibrade-Centro de Cultura,1985.

INEP Matriz de referência do ENEM. 2012. Disponível em: https://bit.ly/30iiwut. Acesso em: 15 set. 2019. 
LABOV, W. Padrões Sociolinguísticos. São Paulo: Parábola, 2008 [1972].

MATTOS E SILVA, R. V. Caminhos da lingüística histórica: ouvir o inaudível. São Paulo: Parábola Editorial, 2008.

MATTOS E SILVA, R. V. Uma compreensão histórica do português brasileiro: velhos problemas repensados. In: MOTA, J.; CARDOSO, S.; MATTOS E SILVA, R. V. (org.). Quinhentos anos da História Lingüística do Brasil. Salvador: Secretaria da Cultura e do Turismo do Estado da Bahia, v. 1, 2006. p. 219-250.

MATTOS E SILVA, R. V. Português brasileiro: raízes e trajetórias. Discursos, São Paulo, n. 3, p. 75-92, 1993.

MENEZES, L. J. J. M. Plurilinguismo, Multilinguismo e Bilinguismo: Reflexões sobre a Realidade Linguística Moçambicana. PERcursos Linguísticos, n. 7, v. 3, p. 81-91, 2013. Disponível em: http://periodicos.ufes.br/percursos/article/view/4589. Acesso em: 20 maio 2020.

MINAYO, M. C. S. O desafio do conhecimento: pesquisa qualitativa em saúde. 10. ed. São Paulo: HUCITEC, 2007.

MOITA-LOPES, L. P. A nova ordem mundial, os Parâmetros Curriculares Nacionais e o ensino de inglês no Brasil: a base intelectual para uma ação política. In: BARBARA, L; RAMOS, R. C. G. Reflexão e ações no ensino/aprendizagem de línguas. Campinas: Mercado das Letras, 2003. p. 29-57.

MOITA-LOPES, L. P. Oficina de lingüística aplicada: a natureza social e educacional dos processos de ensino/aprendizagem de línguas. Campinas: Mercado das Letras, 1996.

NOBRE, A. Quinhentos anos de história social linguística do Brasil: uma retrospectiva. Fórum Linguístico, Santa Catarina, p. 3093-3110, 2018. Disponível em: https://bit.ly/3h0mLjZ. Acesso em: 14 ago. 2019.

OLIVEIRA, G. M. de. Política Linguística e Internacionalização: a língua portuguesa no mundo globalizado do século XXI. Trabalhos de Linguística Aplicada, Campinas, n. 52.2, p. 409-433, jul./dez. 2013.

PETTER, M. M. T. Línguas africanas no Brasil. In: CARDOSO, S.; MOTA, J.; MATTOS E SILVA, R. V. (org.). Quinhentos anos de história linguística do Brasil. Salvador: Secretaria da Cultura e Turismo do Estado da Bahia, 2006. p. 117-142. 
SCHLATTER, M. Celpe-Bras: Certificado de Língua Portuguesa para estrangeiros breve histórico. In: CUNHA, M. J.; SANTOS, P. (org.). Ensino e Pesquisa em Português para Estrangeiros. Brasília: Editora UnB. 1999. p. 97-104.

SCHLATTER, M.; GARCEZ, P. M. Línguas adicionais na escola: aprendizagens colaborativas em inglês. Erechim: Edelbra, 2012. 